\title{
INTERDISCIPLINARIDADE E RESOLUÇÃO DE PROBLEMAS: ALGUMAS QUESTÕES PARA QUEM FORMA FUTUROS PROFESSORES DE CIÊNCIAS
}

\author{
SiLVANA SANTOS \\ Maria Elena Infante-Malachias**
}

RESUMO: Nossa intenção, neste ensaio, é contribuir para o debate sobre o currículo implantado no curso "Licenciatura em Ciências da Natureza" da Escola de Artes, Ciências e Humanidades (EACH) da Universidade de São Paulo, no que concerne especificamente aos construtos interdisciplinaridade e resolução de problemas.

Palavras-chave: Currículo. Interdisciplinaridade. Resolução de problemas. Diretrizes Curriculares Nacionais. Sincretismo de explicações. Formação de professores.

INTERDISCIPLINARITY AND PROBLEM SOLVING: SOME IMPORTANT ISSUES FOR THOSE WHO EDUCATE FUTURE SCIENCE TEACHERS

ABSTRACT: Our intention in this essay is to contribute to the debate about the Natural Science Bachelor course curriculum for the Art, Science and Human Learning School (Escola de Artes, Ciências e Humanidades - EACH) at the University of São Paulo (Universidade de São Paulo - USP), focusing specifically on interdisciplinarity and problem solving.

Key words: Curriculum. Interdisciplinarity. Problem solving. National Teaching Parameters. Explanation syncretism. Teacher education.

Doutora em Genética e pesquisadora do Centro de Estudos do Genoma Humano, Instituto de Biociências da Universidade de São Paulo (USP). E-mail: silvana@ib.usp.br

* Pós-doutora em Genética e em Educação em Ciências e professora da Escola de Artes, Ciências e Humanidades da USP. E-mail: marilen@usp.br 


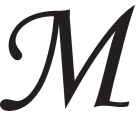
uitos professores de Ciências, da educação básica, enfrentam situações de constrangimento por ensinarem conteúdos de disciplinas acadêmicas para as quais não foram adequadamente formados. Alguns deles, por exemplo, recusam-se a assumir as turmas nas quais são tratados, por tradição, conhecimentos específicos da Física e da Química. Parte desse constrangimento deriva do esquema de formação de professores conhecido por " $3+1$ " concebido na década de 1930 , no qual a formação pedagógica tinha um caráter de complementação para a formação profissional. Na maior parte dos cursos da Universidade de São Paulo, até 2005, para atuar como professor, o estudante ingressava em um curso de bacharelado, completando sua formação com disciplinas da licenciatura, oferecidas pela Faculdade de Educação. Esse esquema sofreu sérias críticas e uma dramática mudança com a aprovação das Diretrizes Curriculares Nacionais para as Licenciaturas pelo Conselho Nacional de Educação. A licenciatura passou a ser entendida como uma carreira com especificidades, para as quais deveria corresponder, portanto, um currículo próprio que cumprisse com a finalidade de formar educadores para atuar na sala de aula.

Neste contexto de reforma curricular, o curso de Licenciatura em Ciências da Natureza para o ensino fundamental da Escola de Artes, Ciências e Humanidades da Universidade de São Paulo (EACH-USP), além de organizar-se sob esse novo prisma, apresenta uma proposta diferenciada no que concerne a sua concepção, pois pretende oferecer ao professor uma visão abrangente e integrada das Ciências da Natureza (Física, Química, Biologia e Geologia) e Matemática, contribuindo para adequar a grade curricular à formação do professor de Ciências e resolvendo, em parte, o seu constrangimento ao ensinar o que não aprendeu.

Nossa intenção, neste artigo, é refletir sobre os dois pilares que fundamentam a formação de professores na $\mathrm{EACH}$ : a interdisciplinaridade e a resolução de problemas. Essa reflexão, entretanto, não responde à necessidade de desenvolver esses construtos com um marco teórico específico da Sociologia da Educação ou Teorias de Currículo; mas à demanda de levantar algumas questóes que alimentam o debate sobre essas abordagens entre os profissionais envolvidos no processo de implantação de cursos de formação de professores. Essas questões discutem o caráter polissêmico desses construtos; a tendência ao sincretismo de explicação e consolidação de práticas híbridas que mesclam distintas concepções sobre o que é esse fazer interdisciplinar e o que significa aprender a resolver problemas. 


\section{A ruptura bacharelado-licenciatura}

As discussões e mudanças propostas para formação inicial de professores da educação básica aconteceram em consequiência das transformaçōes vividas no universo produtivo, emergindo principalmente a partir da década de 1970. Em diferentes continentes, dirigentes políticos de várias tendências buscaram melhorar a produtividade e o crescimento econômico no setor educacional, pois viam uma relação direta entre desenvolvimento econômico e grau de instrução da população ativa, aderindo à idéia de capital humano (De Tommasi, 1998; Azevedo, 2002; Abu-Duhou, 2002; Oliveira, 2004; Santos, 2004). Os conceitos-chave divulgados neste período foram eficiência, produtividade e eficácia, competição, flexibilidade, além das estratégias de gestão democrática ou autônoma das escolas. Essas idéias circularam em fóruns internacionais organizados pela UNESCO, realizados em parceria com agências como o Banco Mundial. Para habilitar a mãode-obra e os consumidores a viverem em um mundo globalizado e informatizado, o capital exerceu forte pressão sobre os Estados para elaboração e implantação de políticas públicas de universalização e melhoria da qualidade da educação básica, entre as quais figurou como chave-mestra, a formação de professores.

Nesse movimento de transformaçōes do universo produtivo e do papel da educação foi promulgada a Constituição Cidadã no Brasil, em 1988, e aprovado, oito anos depois, o substitutivo Darcy Ribeiro que deu origem à nova Lei de Diretrizes e Bases da Educação (LDBEN - Lei n. 9.394/96) (Saviani, 1999). Esta lei conferiu ao Conselho Nacional de Educação (CNE) a incumbência de elaborar as diretrizes curriculares nacionais para os diferentes níveis e modalidades de ensino. As discussōes sobre essas diretrizes angariaram a participação de diferentes entidades civis, como a SBPC, ANPED, CONSED, UNDIME, CNTE, entre outras. Uma das soluçōes encontrada para melhorar a formação inicial dos professores da educação básica foi o rompimento do vínculo bacharelado-licenciatura, por meio da criação de três categorias diferentes de carreiras: o bacharelado acadêmico, o bacharelado profissionalizante e a licenciatura (CNE, 2001).

A partir desse momento, os estudantes, antes de ingressarem na graduação, teriam de optar por um perfil profissional: ou eles seriam docentes em universidades, ou professores de ensino infantil ao médio, ou atuariam como profissionais liberais. Outro aspecto interessante dessa proposta foi a proposição das idéias de "flexibilização da gestão pedagógica" e 
Interdisciplinaridade e resolução de problemas...

“reafirmação da autonomia escolar e da diversidade curricular". Esta flexibilização conferiu às instituições de ensino superior a responsabilidade de elaborar seus projetos pedagógicos, nos quais a organização curricular seria estabelecida. Em outras palavras, as instituições de ensino assumiram daquele momento em diante a responsabilidade de definir o currículo oferecido aos seus graduandos (sobre outros aspectos da flexibilização curricular, ver Catani et al., 2001, e Oliveira, 2004).

No parecer que instituiu as Diretrizes Curriculares Nacionais para a Formação de Professores da Educação Básica (CNE, 2001), torna-se evidente a organização em torno das competências profissionais em vez da tradicional relação de disciplinas, e a inserção de "eixos articuladores", entre os quais figuram a disciplinaridade e interdisciplinaridade. No documento não se encontra nenhuma definição do que seja essa "perspectiva interdisciplinar", tampouco foram sugeridas referências que permitam ao leitor entender mais detalhadamente os preceitos, pressupostos teóricos e as características dessa abordagem. $\mathrm{O}$ excerto do documento diz apenas que:

(...) a formação do professor demanda estudos disciplinares que possibilitem a sistematização e aprofundamento de conceitos e relações sem cujo domínio torna-se impossível constituir competências profissionais. Este domínio deve referir-se tanto aos objetos de conhecimento a serem transformados em objetos de ensino quanto os fundamentos psicológicos, sociais e culturais da educação escolar. A definiçãao do grau de aprofundamento e abrangência a ser dado aos conhecimentos disciplinares é de competência da instituição formadora tomando como referência a etapa da educação básica que o professor irá atuar. No entanto, é indispensável levar em conta que a atuação do professor não é a de um físico, nem biólogo, nem psicólogo ou sociólogo (...). Sendo o professor um profissional que está permanentemente mobilizando conhecimentos de diferentes disciplinas e colocando-as a serviço de sua tarefa profissional, a matriz curricular do curso de formação não deve ser a mera justaposição ou convivência de estudos disciplinares e interdisciplinares. Ela deve permitir o exercício permanente de aprofundar conhecimentos disciplinares e ao mesmo tempo indagar a esses conhecimentos sua relevância e pertinência para compreender, planejar, executar e avaliar situações de ensino e aprendizagem. Essa indagação só pode ser feita de uma perspectiva interdisciplinar". (CNE, 2001, p. 42-43)

Antes que o Conselho Nacional de Educação tivesse sido incumbido de elaborar as diretrizes curriculares para os diferentes níveis e modalidades 
da educação básica pela LDBEN, o Ministério da Educação, então dirigido pelo economista Paulo Renato de Souza, selecionou equipes de especialistas que produziram outros documentos curriculares de referência para os professores: os Parâmetros Curriculares Nacionais (PCN). Por isso, os textos para os diferentes níveis de ensino espelham crenças distintas sobre como organizar o currículo e têm sido alvo de críticas (Bizzo, 2004; Bonamino \& Martinez, 2002; Lopes, 2002). De novo, nestes documentos, a interdisciplinaridade aparece como um princípio ou "eixo articulador". Entretanto, não é explicitada a compreensão que o professor deve desenvolver sobre esta abordagem. Por exemplo, não é trivial diferenciá-la da pluri ou multidisciplinaridade.

Diante do exposto, verifica-se, por um lado, que não existe uma explicitação do significado da interdisciplinaridade nos documentos oficiais, embora seja reconhecida como um "eixo articulador" nas diretrizes curriculares e "uma abordagem" didática imprescindível nos PCNs. O construto interdisciplinaridade certamente é polissêmico, todavia, as propostas curriculares devem explicitar quais são as idéias sobre interdisciplinaridade sobre as quais o trabalho do professor deve se sustentar, e isto não é tratado nos documentos oficiais, nem são oferecidas referências às quais o professor possa se debruçar para compreender o que está sendo sugerido a ele. Por outro lado, o processo de elaboração desses documentos oficiais, quer sejam as diretrizes curriculares fixadas pelo CNE ou os PCNs produzidos por especialistas do MEC, ocorreu em consonância com o movimento de transformação da educação em nível global, na qual a palavra de ordem é flexibilização e, por isso mesmo, o Estado delegou a sua responsabilidade de definir o conteúdo a ser apreendido em cursos de formação de professores para as instituições de ensino superior.

Nos últimos vinte anos, propostas curriculares semelhantes às escritas anteriormente foram levadas a cabo, por exemplo, em universidades americanas. Segundo Payne (1999), de 410 programas de diferentes instituições analisados por Edwards em 1996, 280 deles destacaram a utilização de abordagens interdisciplinares em seus currículos. A mudança mais comum verificada nesses programas foi a incorporação da perspectiva feminista e das discussões étnicas e multiculturalistas. De 1986 até 1996, o crescimento das instituições que ofereciam programas interdisciplinares passou de $36 \%$ para $75 \%$. Esse movimento das universidades americanas em prol da interdisciplinaridade usualmente focava sobre tópicos, assuntos ou questóes que pudessem ser tratados por diferentes 
Interdisciplinaridade e resolução de problemas...

disciplinas. Por exemplo, um dos programas desses cursos tratava do desenvolvimento sustentável na América Central, o qual abrangia o estudo de conceitos da Geografia, Economia, Ciências Políticas, Sociologia e Ciências Ambientais. A característica dessa abordagem interdisciplinar, portanto, era o tratamento sobre um determinado conteúdo sob "visōes" ou paradigmas de várias disciplinas. Entretanto, em nenhum momento, foram explicitados nos programas quais seriam os critérios usados para selecionar as teorias e os conceitos recortados das diferentes disciplinas.

Apesar desse amplo movimento nas escolas americanas para introdução de perspectivas interdisciplinares em seus currículos, não se alcançou ainda na literatura consenso sobre qual seria o significado mais apropriado para interdisciplinaridade e, por conseguinte, o que caracterizaria as práticas pedagógicas sustentadas por este conceito. Por exemplo, Klein (1990) argumenta que a interdisciplinaridade não é corpo de conteúdos ou assuntos, mas o processo para construção de sínteses integrativas, um processo que se iniciaria com um problema, uma questão, um tópico ou assunto. A interdisciplinaridade consistiria em um processo de construção de conhecimento que se sobrepõe à fragmentação, à especialização e à tendência de produção de um conhecimento híbrido. Em contraste, para Keesey (1998), basta tratar conteúdos, métodos ou utilizar estratégias de pesquisa de diferentes disciplinas para que se produza uma prática interdisciplinar. Outros autores, como Romm (1998) e Stember (1991), preferem construir tipologias específicas para diferenciar práticas intra, multi, inter e transdisciplinares. Para Romm, a interdisciplinaridade se caracterizaria pela investigação orientada para a reflexão; já, para a segunda autora, seria a prática orientada para integração de idéias e achados de diferentes disciplinas. Por vezes, as abordagens interdisciplinares têm sido associadas às práticas inseridas nas discussóes da pós-modernidade, vinculando-se ao radicalismo político, movimento feminista e multiculturalista (Newell, 1997). Essas diferentes perspectivas atestam que existem muitos entendimentos sobre o que seria "abordagem interdisciplinar”, por vezes, conflituosos e divergentes. Em virtude da inexistência de uma clara exposição do que seja e dos procedimentos para concretizar uma prática docente interdisciplinar, tomaremos a proposta curricular do curso de Licenciatura em Ciências da Natureza da EACH-USP como objeto de análise e reflexão, com a finalidade de levantar algumas questôes de relevância para a formação de professores. 
Não almejamos, contudo, realizar uma análise a partir de referenciais próprios das Teorias de Currículo ou da Sociologia da Educação. Neste artigo, propomo-nos a levar as nossas próprias dúvidas e questionamentos aos profissionais que formam professores, e discutir as possíveis implicações da implantação de uma proposta pedagógica que pretende oferecer aos seus graduandos uma "visão integrada da Ciência". A nossa análise tomará como objeto os dois construtos que sustentam não apenas o curso de licenciatura, mas também todos os dez cursos da EACH: interdisciplinaridade e resolução de problemas. Essa proposta curricular, por conseguinte, terá certamente influência sobre a construção de conhecimento acerca do fazer didático pelos futuros professores. Por isso, é fundamental refletirmos cuidadosamente sobre essas práticas educativas em um curso de formação de professores e, mais do que isso, investigar cuidadosamente "o que os graduandos desse curso estão aprendendo" e "o que os docentes estão ensinando", com a finalidade de sistematizar conhecimentos sobre a contribuição de organização curricular específica sobre a formação de professores.

\section{Um curso para formar professores de Ciências}

O curso de graduação Licenciatura em Ciências da Natureza pretende formar professores de Ciências preparados para ensinar conteúdos de diferentes disciplinas (Física, Biologia, Química, Astronomia, Geologia e Matemática), como sugere o excerto colhido no site da unidade: "as Ciências da Natureza estudam, de maneira integrada, física, química, ciências da vida e da terra, propiciando o conhecimento da natureza como um todo" (disponível em: http: |www.uspleste.usp.br).

Embora a EACH tenha rompido com a organização departamental imposta pela reforma universitária regulamentada pela Lei n. 5.540/68, ela manteve disciplinas semestrais associadas a determinados créditos. No ciclo básico, com duração de um ano letivo, a grande inovação foi a criação da disciplina Resolução de Problemas, na qual os estudantes são convidados a desenvolver projetos. Os docentes atuam como tutores para um grupo de 12 alunos, os quais são, por sua vez, inclusos em grupos de 60 alunos com representantes de diferentes cursos. Com isso, humaniza-se a relação professor-aluno e abre-se um espaço privilegiado para o diálogo, como descreveremos mais detalhadamente a seguir. Por um lado, 
Interdisciplinaridade e resolução de problemas...

foi instituído o ciclo básico para todos os cursos, com disciplinas que respondem, de certa maneira, à demanda de discussões pós-modernas, como multiculturalismo, feminismo, violência, direitos humanos e questões étnicas, à semelhança do movimento das escolas americanas. Por outro lado, no primeiro ano da Licenciatura em Ciências da Natureza, o graduando passa a tomar contato com disciplinas pedagógicas específicas como sugerido pelo Programa de Formação de Professores da USP (Carvalho, 2004).

Em relação à organização da grade específica, percebe-se que houve uma evidente preocupação em expor o estudante aos conteúdos de diferentes campos de conhecimento, como se verifica, por exemplo, no elenco de disciplinas oferecidas no terceiro semestre: Astronomia do Sistema Solar, Modelagem Matemática, História Natural, Organização e Expressão do Material Genético e Engenharia Genética, Psicologia da Educação e Laboratório de Física. Não percebemos, no entanto, elos que relacionem explicitamente o conteúdo dessas disciplinas - conteúdos estes descritos detalhadamente nas ementas das disciplinas publicadas na página web da USP. Aparentemente, essa organização da grade retoma a tradição curricular da escola básica: na quinta série se ensina o Sistema Solar, na sexta série, seres vivos (História Natural) e um pouco de Física. Esta impressão de justaposição se repete na análise do conjunto de disciplinas oferecido no quarto semestre: Sistema Terra 1; Funçôes de várias variáveis; Linguagem Quimica e Reaçôes Quimicas; Estrutura e Funcionamento da Educação Básica no Brasil, História e Filosofia da Ciência. Verifica-se, também, menor presença da Física em relação à Biologia, aspecto que está em processo de discussão e deve sofrer alguma alteração antes da publicação deste artigo.

Cabe perguntar: Quais foram os critérios usados para agrupar essas disciplinas? Em nenhum momento, na apresentação da grade curricular, eles foram explicitados, tampouco se consegue apreender facilmente qual seria o "elo" ou "eixo articulador" entre as diferentes disciplinas, o que caracterizaria assim a abordagem interdisciplinar exceto pelo fato de que são tratados conteúdos das diferentes disciplinas acadêmicas, o que já é em si positivo, mas talvez não seja suficiente. Para explicitar o que seriam esses elos curriculares, poderíamos imaginar, por exemplo, a História da Ciência não como uma disciplina específica da grade, mas como um eixo articulador. Dessa maneira, ao estudante seria feito o convite para uma verdadeira viagem no tempo, a fim de que ele 
aprendesse, dentro do contexto histórico, como surgem e são refutadas as teorias científicas. Para tratar do nascimento da ciência moderna, os alunos poderiam ler $O$ método, de Descartes, e estudar as leis do movimento desenvolvidas por Newton, bem como os fundamentos do cálculo. Neste processo, eles poderiam entender como e quais foram as condições materiais e históricas associadas à elaboração das idéias newtonianas. Discutiriam arduamente quais perguntas estavam sendo debatidas na comunidade científica daquele tempo e vivenciariam, se possível, o contexto daqueles debates. Um dos materiais de apoio para ilustrar essa abordagem do curso poderia ser a coleção de documentários conhecida por Universo Mecânico. Neste caso, a organização curricular estaria fundamentada na contextualização histórica como eixo articulador.

Outra maneira de organizar o currículo seria tomar como "eixo articulador" a metodologia de ensino. De novo, em vez de configurar como uma disciplina, a metodologia seria parte integrante de outras disciplinas. Por exemplo, ao tratar do Sistema solar, o docente seria convidado a considerar o conceito de assimetria invertida, ou seja, entenderia a sua prática docente como um modelo de atuação para o futuro professor. Ao ministrar suas aulas, o docente ensinaria o conteúdo específico de sua disciplina como também aspectos de natureza pedagógica associados ao ensino daquele conteúdo em particular para as crianças da educação básica. Ora, se fosse assim, haveria "aprendizado em mão-dupla”, pois o futuro professor teria de refletir sobre os aspectos metodológicos de sua prática em todas as disciplinas do curso e, em paralelo, os docentes das disciplinas específicas teriam de fazer um grande esforço de aprender a refletir sobre questôes afins, aperfeiçoando, assim, a sua própria prática. Não estamos seguras, no entanto, se a metodologia cumpriria com a função de "forçar" a interdisciplinaridade entre as disciplinas pedagógicas e aquelas das ciências básicas, ou se ela seria um tema transversal. No caso dos PCNs, por exemplo, a educação ambiental é um tema transversal tratado no seio de diferentes disciplinas e não se constitui por si própria uma disciplina específica.

Uma abordagem interdisciplinar poderia caracterizar-se pela existência de um objeto de interesse comum a diferentes disciplinas. Por exemplo, a Anatomia, a Citologia e Embriologia e a Fisiologia desenvolveram-se graças aos seus diferentes métodos de estudos. Quando um estudante de Medicina ou de Ciências Biológicas estuda os sistemas existentes nos seres vivos, como o digestório, respiratório, nervoso e endócrino, isso é feito de 
maneira fragmentada. Estuda-se, assim, o sistema nervoso na Anatomia, depois de novo na Fisiologia e assim por diante. Uma alternativa para estudar o sistema nervoso, em uma perspectiva interdisciplinar, seria tomá-lo como objeto e expor os conhecimentos sobre este sistema oriundos das diferentes disciplinas: o sistema nervoso sob o foco da anatomia, da embriologia, da fisiologia etc. Contudo, o que torna esta abordagem interdisciplinar em relação à outra? Basicamente é a apresentação de um mesmo objeto - o sistema nervoso -, considerando os conhecimentos produzidos por distintas disciplinas, as quais se caracterizam, por sua vez, pelo uso de distintos métodos e técnicas de investigação. No tratamento tradicional, um mesmo método é aplicado para se estudar diferentes sistemas. Não foram sistematizados, entretanto, conhecimentos que permitam afirmar, com base em evidências empíricas, que uma abordagem é mais eficiente do que a outra.

\section{Interdisciplinaridade não é antônimo de especialização}

A produção acadêmica está inserida no universo produtivo e sofreu uma expansão vertiginosa nos últimos anos. No Brasil, isto se verifica pelo número de alunos matriculados, por exemplo, em programas de mestrado e doutorado que, de 1987 a 1996, em menos de dez anos, passou de 8.000 para 22.000 (Durham, 2005). O número de artigos publicados cresceu praticamente em escala logarítmica. Para quem atua no campo da produção de conhecimento científico, em virtude desse crescimento, tornou-se praticamente impossível que um especialista leia todas as publicações de sua área. Ao estudar um objeto qualquer, os pesquisadores têm de usar lentes mais potentes e métodos cada vez mais sofisticados, o que restringe, evidentemente, seu campo de visão.

Na literatura nacional (Jupiassu, 1976; Queluz, 2003; Fazenda, 2005), tem-se entendido essa fragmentação como uma verdadeira "patologia" da modernidade e não como um passo necessário ao desenvolvimento da Ciência. Se o pesquisador reduz seu campo de visão para conhecer em maior profundidade seu objeto de estudo, isto não é ruim ou bom, é simplesmente o resultado de um processo histórico que permite a produção de novos conhecimentos naquela área específica. Ora, como não vemos sentido em dizer que uma lente de um microscópio é melhor ou pior do que outra, tendo em vista que cumprem com funçôes diferentes, não compreendemos os argumentos daqueles que transformam a 
especialização em uma doença a ser erradicada pelo uso redentor de abordagens interdisciplinares e holísticas (veja, por exemplo, as críticas a essa abordagem em Jantsch \& Bianchetti, 2004).

Diferente do pesquisador universitário, a atuação de um professor da educação básica ou jornalista demanda formação genérica e menos especializada. Esses profissionais devem usar, necessariamente, lentes diferentes daquelas utilizadas pelos especialistas, pois precisam vislumbrar, para cumprir com sua função social, distintos aspectos de um objeto ou uma realidade. Isso porque esses profissionais atuam como divulgadores do conhecimento científico produzido pelos especialistas, mas eles próprios não são especialistas. Para dar conta dessa função, sem dúvida alguma, eles precisam conhecer, mas não extensa e detalhadamente, os conhecimentos produzidos em diferentes disciplinas. $\mathrm{O}$ educador e o jornalista são, portanto, elos entre a ciência e a sociedade.

Em virtude da expansão na produção de informação e a crescente especialização, tornou-se particularmente problemática a formação do professor de Ciências. "Quanto?" e "O quê?" deve ser ensinado aos futuros professores sobre as diferentes disciplinas para que consigam atuar como interlocutores entre os especialistas e os cidadãos? Ora, como esses professores conseguirão atualizar-se diante da crescente expansão da produção de conhecimento? Como se manterão informados sobre as mudanças em, pelo menos, cinco campos de produção de conhecimento distintos (Física, Química, Biologia, Astronomia, Ciências da Terra, Educação e Psicologia)?

\section{Interdisciplinaridade ou sincretismo?}

Uma das características da apropriação de conhecimento pelos indivíduos na sociedade pós-moderna e informatizada é a tendência de associar indiscriminadamente conhecimentos provindos de diferentes esferas de produção, construindo, assim, explicações idiossincráticas e sincréticas. $\mathrm{O}$ conceito de sincretismo foi proposto inicialmente por Piaget (1959) e desenvolvido por Santos (2005 e 2006). Como o conhecimento científico circula pelos meios de comunicação em paralelo aos conhecimentos cotidianos, as pessoas tendem a associá-los desrespeitando o enorme abismo existente nos seus modos de produção e seu poder de predição. Para dar uma idéia sobre o que seja sincretismo e suas conseqüências sobre a construção de conhecimento, servimo-nos de uma 
analogia com a novela Bang-bang, exibida pela Rede Globo de Televisão. No contexto do Velho Oeste americano, entre cowboys, surgem as figuras do "Zorro" espanhol, de Freud e de uma baiana brasileira. Se fossem respeitados os contextos históricos e geográficos desses personagens, jamais eles coexistiriam em um mesmo espaço e tempo. Ora, ao acessar a internet, em telas sobrepostas, convivemos com imagens e histórias diferentes e, em consequiência disso, as pessoas perdem o discernimento sobre a origem e validade das informações transmitidas e sua referência histórica. Por conseguinte, todos os conhecimentos passam a ser incorporados e reunidos em um verdadeiro mosaico. Na literatura, alguns autores utilizam o termo ecletismo e hibridismo para referir-se ao que conceituamos por sincretismo de explicações, mantendo a originalidade de Piaget.

$\mathrm{Na}$ formação do professor de Ciências, é necessário zelar pela compreensão contextualizada dos conteúdos das diferentes disciplinas. Não basta oferecer "um pouquinho" de conhecimento de cada uma dessas disciplinas e relegar aos alunos a tarefa de compreendê-lo de maneira adequada. Por força do fenômeno do sincretismo, os alunos tenderão a relacionar e conectar explicações, conhecimentos e conceitos indiscriminadamente, dando origem a um novo conjunto de conhecimentos idiossincráticos desprovidos, muitas vezes, de validade científica. Por isso, a formação generalista carrega consigo alguns desvios, os quais devem ser estudados sistematicamente para apreendermos o impacto da implantação de currículos multidisciplinares (ou interdisciplinares?) sobre o processo de construção de conhecimentos pelos indivíduos.

Face à sua relevância, este é um dos objetos de estudo sobre os quais os docentes da EACH terão de se debruçar e compreender em profundidade para que possamos avaliar, com dados empíricos, o processo de formação de professores com base nessa visão de "oferecer um pouquinho de conhecimento sobre os distintos campos de conhecimento". Entendemos que este currículo é multidisciplinar porque os especialistas contribuirão com seu conjunto de conhecimentos específicos para a formação do futuro professor, mas não se revela, na proposta curricular, nenhum eixo que articule esse currículo e explicite sua natureza interdisciplinar.

Embora a interdisciplinaridade, entendida como o conhecimento resultado do esforço de colaboração de especialistas em campos de produção distintos, seja uma idéia que já vem sendo debatida há muitos 
anos, poucas evidências foram colhidas no sentido de mostrar sua influência sobre a construção de conhecimento científico pelos estudantes de diferentes níveis de ensino e na formação de professores. Por um lado, os futuros professores formados pela EACH terão acesso a uma versão reduzida do conhecimento produzido em uma disciplina. Por outro lado, a construção de conhecimentos em uma disciplina, entendida aqui como Biologia ou Física, implica não somente o domínio de um conjunto de conceitos e teorias, mas valores e atitudes característicos daqueles profissionais que militam naquele campo de estudos. Ao longo dos anos, por exemplo, o graduando de um curso de Física adquire não somente conhecimentos, mas se apropria de valores e de uma "visão de mundo" compartilhada entre os profissionais que atuam naquele campo.

Como argumentou Bauer (1990), as disciplinas acadêmicas são análogas às diferentes "culturas", pois elas não divergem apenas em relação aos seus objetos e métodos de estudo, mas ao que consideram e aceitam como valores no grupo. Isso se torna mais evidente quando comparamos as "visões de mundo" e os valores de profissionais das ciências humanas e básicas. As diferenças, certamente, ultrapassam a definição de seus objetivos de estudo e procedimentos; dizem respeito ao que se considera como conhecimento reprodutível, válido ou verdadeiro; ao valor da capacidade de predição de uma teoria; enfim, ao que é ou não aceito como produto da ciência em seus territórios. Por exemplo, na ciência básica - entre químicos, geneticistas e físicos-, um dos critérios utilizados para classificar a relevância de um conjunto de conhecimentos ou descobertas é o índice de impacto do periódico onde foi publicado. Muitas vezes, cientistas sociais se mostram avessos à idéia de "quantificar" ou "qualificar" a produção acadêmica por meio desses índices de impacto. Este é apenas um pequeno exemplo dos diferentes valores compartilhados por profissionais em diferentes territórios de produção de conhecimento.

Organizados em uma só equipe, os docentes da EACH-USP se defrontam com a incumbência de desenvolver uma proposta pedagógica interdisciplinar (ou multidisciplinar?). Esses profissionais devem romper com suas "culturas" próprias, o que significaria refletir sobre as bases epistemológicas e os valores de grupo que sustentam diferentes disciplinas. Por serem especialistas, esses docentes estão imersos em "visões de mundo" muito diferentes, o que pode funcionar como barreira para compartilhar decisões sobre o que ensinar. De qualquer maneira, o graduando estará, possivelmente, em contato com valores muito diferentes 
Interdisciplinaridade e resolução de problemas...

e, por vezes, contraditórios. Neste contexto, consideramos pertinente perguntar: Que visão de ciência os futuros professores de Ciências construirão após a conclusão de seu curso de Licenciatura em Ciências da Natureza?

\section{Uma disciplina para ensinar a resolver problemas}

Outra "inovação" introduzida no currículo do curso de formação de professores da EACH foi a disciplina Resolução de Problemas (RP); na qual grupos de 12 alunos são orientados por um docente, cuja missão é desenvolver um projeto para explorar um problema definido por eles com base em um tema comum.

Se pensarmos especificamente no construto "resolução de problemas", podemos situá-lo em três perspectivas teóricas e metodológicas bastante distintas (Berbel, 1998; Cyrino \& Toralles-Pereira, 2004). Identificada com as idéias da Escola Nova de Dewey, essa estratégia pode ser sinônimo de "aprendizagem baseada em problemas", ou abordagem Problem-Based Learning (PBL), a qual surgiu e se desenvolveu no seio das escolas médicas americanas a partir da década de 1960. Em outra frente, resolução de problemas poderia ser entendida como o passo da problematização preconizada por Paulo Freire, sendo, portanto, parte de um processo mais complexo de integração da prática e da reflexão para libertação do indivíduo. A resolução de problemas, em uma terceira perspectiva, poderia associar-se à atividade científica, ou seja, às estratégias utilizadas por investigadores para a produção de conhecimento científico. Essas diferentes perspectivas não podem ser tomadas simplesmente como sinônimos, pois em cada uma delas a resolução de problemas cumpriria com um papel diferente, funcionando, assim, como um conceito que fundamenta determinada estratégia didática com justificativas teóricas e práticas diferentes. Na EACH, a disciplina Resolução de Problemas possui características dessas diferentes abordagens, o que pode, de novo, funcionar como alavanca ou empecilho para a formação de professores. Para explicitar mais claramente esta ponderação, faz-se necessário apresentar, ainda que sucintamente, as três perspectivas citadas antes de retomar a questão.

Resolução de problemas na perspectiva da PBL

Problem-Based Learning (PBL) consiste em um método de ensino nascido em meados da década de 1960 na escola médica da Universidade 
McMaster, sendo alvo de inúmeras publicações e estudos nos últimos anos. Cabe ressaltar que os problemas são, tradicionalmente, apresentaçôes de casos clínicos, elaborados cuidadosamente pelos tutores, com os quais os estudantes de Medicina se defrontarão em sua prática profissional. A grande vantagem dessa abordagem é a proposição de situaçôes sobre as quais os estudantes podem refletir, usando obrigatoriamente conhecimentos de diferentes disciplinas e treinando o raciocínio para elencar diferentes hipóteses diagnósticas, o que permite desenvolver procedimentos-padrão e simular a tomada de decisão.

Para resolver os problemas propostos pelos tutores, os alunos explicitam suas hipóteses e conhecimento prévio, buscam informações em livros-texto e, com auxílio do tutor e colegas de trabalho, refutam as soluçōes menos prováveis, elaborando explicaçōes para o fenômeno observado com a utilização dos conceitos e conhecimentos de diferentes disciplinas. Por exemplo, um desses problemas seria o caso de uma universitária que se queixa de dores abdominais e, com aplicação de relaxante muscular, essas dores se reduzem drasticamente. Na discussão sobre o caso, são inseridas novas informaçoes, quando requeridas, até que o grupo defina um diagnóstico e liste os procedimentos para tratamento.

Sob o ponto de vista da psicologia cognitiva, existem evidências de que o uso da abordagem PBL oferece uma série de condiçôes para aprendizagem de conhecimento factual e habilidades de raciocínio que confere maior competência ao profissional. O primeiro aspecto positivo dessa abordagem é a aprendizagem conceitual no contexto em que o conhecimento será utilizado; a segunda é a explicitação do conhecimento prévio do estudante que facilita a acomodação de conhecimentos novos e, por fim, o estudante se apropria de exemplos que podem servir de modelos ou padrōes para solução de outros problemas semelhantes e, com isso, ele constrói uma rede de conceitos e modelos de ação (Boud \& Feletti, 1997).

Em relação à aprendizagem conceitual, é consenso no campo da psicologia cognitiva que o conhecimento previamente existente na mente do aprendiz determina quanto ele pode aprender. Quando se utiliza a abordagem PBL, os estudantes têm de descrever tudo o que sabem sobre o assunto e suas hipóteses iniciais. Ao dialogar com colegas e tutores, eles se defrontam com outras idéias sugeridas por seus colegas e, com auxílio do tutor, organizam uma sequiência de estudos e revisōes sobre os conhecimentos das diferentes disciplinas acadêmicas necessárias à resolução do 
caso. O estudante, ao explicitar para si mesmo o que ele conhece sobre aquele assunto e o que não conhece, constrói para si estratégias de aprendizagem e de metacognição fundamentais para a sua prática profissional. Além disso, como os conceitos são apreendidos dentro de um contexto, eles são mais facilmente memorizados e acessados quando requeridos (Norman \& Schmidt, 1992).

Outros dois aspectos que merecem menção são o desenvolvimento da habilidade de tomar decisóes refletidas em curto espaço de tempo e a motivação. Quanto mais o estudante exerce a prática de refletir sobre situações e problemas que simulam a prática cotidiana e a tomada de decisões, certamente mais habilitado esse profissional estará para ingressar no mercado. Defrontar-se com situações reais por si só funcionam como elemento de motivação, pois elas inserem o futuro profissional no contexto de sua atuação e criam um ambiente próprio para a reflexão. Os alunos jamais se perguntariam "por que eu tenho de aprender isso?", tendo em vista que o uso do conhecimento é evidente. Por fim, vale ressaltar que esse método desenvolve no estudante a competência de "aprender a aprender". Em sua vida cotidiana, o profissional tem de aprender a buscar informações e se atualizar em relação aos novos conhecimentos e teorias produzidas em sua área de atuação. E a resolução de problemas sob o prisma da abordagem PBL literalmente treina o estudante para fazer isso.

Resolução de problemas na perspectiva da problematização de Paulo Freire

Na perspectiva de Paulo Freire, a educação não pode ser reduzida a uma concepção bancária, como se o conhecimento fosse depositado cédula por cédula na mente dos estudantes, ou como se as pessoas fossem jarras vazias passíveis de serem preenchidas pelo conhecimento dado. Ao contrário disso, a problematização induz as pessoas a refletirem sobre sua relação com o mundo. Sob essa perspectiva, a construção de conhecimentos ocorre a partir das vivências e experiências cotidianas dos estudantes. Apoiada em um processo de aprendizagem por descoberta e não por recepção, os conteúdos de ensino não são oferecidos aos estudantes em sua forma acabada, mas são alvos de intensa discussão, na qual os professores e estudantes estabelecem uma relação dialógica, quer dizer, um diálogo 
cuja relação de autoridade não é autoritária, em que ambos os indivíduos compartilham conhecimentos e aprendem uns com os outros.

Ao observar a realidade e dialogar sobre ela, os estudantes se defrontariam com problemas em um cenário real, ou seja, não seriam elaborados a priori por um grupo de tutores como na abordagem PBL. Esses questionamentos da vida cotidiana manifestam-se em sua complexidade e contradições, evidenciando as relações desiguais e a dominação de determinados grupos sobre outros. Por isso, o trabalho pedagógico na perspectiva da problematização de Paulo Freire possui intrinsecamente um caráter político. Não basta conhecer o mundo e perceber as relações e contradiçôes nele existentes, o aprendizado tem de estar inserido em uma perspectiva transformadora. A ação de identificar problemas em um determinado contexto histórico permite a reflexão sobre os condicionantes dessa realidade e a proposição de ações para transformá-la. Por isso, a problematização faz parte de um movimento de questionamento e entendimento visando à transformação da realidade social, a famosa tríade ação-reflexão-ação.

A perspectiva da problematização freireana está inserida na pedagogia crítica, que entende a exploração do trabalho na sociedade capitalista como alienante e prega, portanto, a libertação do indivíduo e sua atuação política para redução das desigualdades sociais. Os problemas, neste caso, longe de serem elaborados cuidadosamente por um grupo de tutores, são originais e surgem do dialogo dentro do grupo composto por estudantes e professor. Em virtude de sua originalidade, o planejamento didático e o levantamento bibliográfico não podem ser organizados a priori, o que acarreta certa insegurança aos docentes.

A "resolução de problemas" dentro de abordagem baseada em problemas (PBL) consiste em uma estratégia que visa desenvolver as habilidades cognitivas para integração de conhecimentos das diferentes disciplinas acadêmicas e a tomada de decisão em relação a problemas previamente elaborados pelos docentes, os quais simulam situaçóes reais a serem enfrentadas na prática profissional. Diferente dessa perspectiva, a resolução de problemas entendida como problematização necessariamente tem de partir da realidade social dos estudantes e visa claramente à reflexão sobre os condicionantes de uma realidade a fim de transformála. Portanto, a problematização não parte de problemas previamente definidos, mas surge da observação e do diálogo sobre a vida cotidiana. 
Interdisciplinaridade e resolução de problemas...

Resolução de problemas na perspectiva da produção de conhecimento científico

A resolução de problemas ainda pode ser entendida dentro do contexto da simulação da produção de conhecimento de natureza acadêmica, análoga à disciplina de "iniciação científica". Neste caso, o estudante ou o orientador proporia uma investigação de natureza científica para pesquisar um objeto específico ou um problema acadêmico. Ao longo desse processo, seria definida uma pergunta, a qual seria respondida de maneira teórica, por meio de uma revisão crítica cuidadosa da literatura, ou de uma pesquisa empírica com coleta de dados e interpretação. Se a resolução de problemas é entendida no contexto da ciência, então a função primeira desse processo de ensino e aprendizagem é permitir ao estudante vivenciar o cotidiano acadêmico para que ele possa compreender como o conhecimento científico é produzido.

Os "problemas" dentro do campo da ciência possuem algumas peculiaridades. Qualquer que seja a investigação, o pesquisador não pode estudar um problema como se este brotasse em sua mente. Se fosse assim, estaríamos reinventando e recriando o que já foi descoberto ou estudado há muito tempo. Uma das características da produção científica é o seu caráter coletivo. Para colocar um novo "tijolo no edifício científico", a primeira questão a ser definida é "onde colocar?", ou seja, definir o que já foi feito e saber exatamente qual é a contribuiçăo que se pretende fazer. Por isso, é fundamental que o pesquisador realize uma extensa revisão bibliográfica sobre o assunto de seu interesse, sumariando as questôes já pesquisadas e as conclusôes consensuais. Em seguida, define-se uma questão específica a ser respondida por meio de uma metodologia referendada por outros pesquisadores. Como foi dito antes, esta pergunta pode ser de natureza teórica ou empírica. De qualquer maneira, não basta responder à questão para si mesmo. Parte do trabalho consiste em redigir artigos e publicações por meio dos quais são compartilhadas idéias e descobertas, as quais constituem contribuiçôes para a construção coletiva e pública do conhecimento científico.

Diferente da abordagem PBL, os problemas dentro do contexto de uma investigação científica são originais e têm de contribuir para entendimento de uma questão específica de relevância para a comunidade acadêmica, tendo ou não uma aplicação direta para a sociedade. Para Paulo 
Freire, os problemas também teriam de ser originais, mas deveriam estar relacionados à realidade cotidiana, onde os estudantes seriam quase que "pedras no sapato dessas pessoas". Estes problemas, geralmente atrelados à questão da desigualdade social, são alvo de uma reflexão coletiva que desencadeia a proposição de ações que visam transformar a realidade observada, ou seja, a reflexão a partir da observação da realidade leva a uma ação transformadora sobre esta realidade. Os problemas "científicos" podem ou não estar associados a uma questão de cunho social, pois os objetos e os níveis de análise são muito diversos na ciência.

Para concluir esta apresentação, cabe ressaltar os diferentes valores e resultados esperados quando da aplicação da estratégia "resolução de problemas" considerando as diferentes perspectivas apresentadas anteriormente. Em uma disciplina como Resolução de Problemas, oferecida para um curso para formação de professores, pode-se tanto simular a produção de conhecimento acadêmico como tentar transformar uma situação do entorno, de maneira semelhante à metodologia de problematização de Paulo Freire. A chave, neste caso, é entender que os resultados e os valores construídos no grupo, fruto desses esforços, são muito diferentes. No primeiro caso, o estudante deve encontrar um problema que seja de interesse acadêmico e produzir conhecimento a partir de uma investigação sobre uma questão específica. No segundo caso, da problematização, o produto necessariamente é uma ação que visa transformar uma dada realidade. Esta ação pode ser um documento encaminhado para autoridades solicitando algo para uma comunidade, um encaminhamento mais direto como a promoção de mutirão de limpeza, plantio ou de saúde. Por fim, resta fechar esta apresentação discutindo qual é o produto da abordagem da aprendizagem baseada em problemas (PBL). Este produto não é tão palpável quanto os anteriores, pois consiste no adestramento do pensamento para resolver problemas da prática profissional. O ganho está no próprio treinamento do raciocínio, o estudante exercita seu pensamento para tornar mais eficiente a sua prática profissional.

\section{Uma reflexão necessária para um curso de formação de professores}

$\mathrm{Na} \mathrm{EACH}$, a proposta da disciplina Resolução de Problemas combina ou mescla idéias das três diferentes perspectivas apresentadas de maneira não sistematizada e, portanto, sincrética; contribuindo para a consolidação de práticas que são pautadas em pressupostos diferentes 
Interdisciplinaridade e resolução de problemas...

daqueles que as fundamentariam oficialmente - o Problem BasedLearning (PBL). Por exemplo, muitas vezes, os estudantes se engajam em questôes comunitárias buscando alternativas para saná-las, fazendo uso inadequado, no entanto, do "método científico". Se os graduandos têm a intenção de resolver um problema social, então o produto, neste caso, deve ser uma intervenção e não apenas o registro ou a descrição da realidade. Se a intenção é simular a produção de monografias científicas, então o foco do trabalho deve ser a elaboração de uma revisão bibliográfica abrangente e não o engajamento em movimentos sociais. Certamente, os projetos que vêm sendo desenvolvidos na disciplina não se encaixam na perspectiva original do PBL, pois esta se baseia em estudos de casos específicos com vistas a aperfeiçoar a prática profissional.

Parece-nos, portanto, essencial a sistematização de conhecimentos sobre o que fundamenta a disciplina Resolução de Problemas sob o ponto de vista teórico e metodológico. É necessário descrever as características das práticas desenvolvidas na EACH e distingui-las claramente daquelas baseadas em PBL, desenvolvendo um modelo próprio para a disciplina que responda tanto às demandas de natureza socioeconômica e cultural que cercam a universidade, quanto às diferentes especificidades dos cursos de graduação oferecidos pela EACH.

Esta discussão torna-se particularmente importante no curso de Licenciatura em Ciências da Natureza, pois, para pensar sobre a resolução de problemas existentes na sala de aula, no contexto escolar ou na comunidade na qual a escola se insere, o professor precisa vivenciar, em sua formação, práticas que sejam modelo para a sua atuação. Os professores precisam aprender a consolidar equipes de trabalho que identifiquem problemas específicos, saibam realizar pesquisa bibliográfica consistente e, coletivamente, discutam e encaminhem soluçôes para tentar resolvê-los. Nenhum professor conseguirá, isolado de seus pares, entender e refletir sobre as questôes e problemas com os quais se depara em uma sala de aula. Em um curso de formação de professores, é absolutamente fundamental que o graduando vivencie a prática de colaborar e trabalhar em grupo com metas comuns. Entretanto, para ensinar isso aos seus alunos, os docentes da Escola de Artes e Ciências Humanas (EACHUSP) terão de aprender a fazê-lo também, superando o isolamento característico da docência universitária e sistematizando um conjunto de conhecimentos sobre o próprio processo de construção curricular em que são atores. 
Uma proposta interdisciplinar que enriqueça a formação universitária dos seus alunos precisa ser fundamentada teoricamente e compreendida por todos os seus membros (Infante-Malachias \& Correia, 2007). É necessário que os profissionais envolvidos no processo de criação e implantação de grades curriculares baseadas na interdisciplinaridade e na resolução de problemas reflitam sobre a sua própria formação disciplinar e dialoguem sistemática e continuamente com os profissionais de outras áreas, com a intenção de produzir conhecimento teórico e empírico que possa orientar e alimentar as transformaçóes requeridas nos currículos de cursos de graduação e, mais do que isso, seja modelo de atuação coletiva para os graduandos que estão inseridos nesse processo.

Recebido em agosto de 2007 e aprovado em abril de 2008.

\section{Referências}

AZEVEDO, J.M.L. Implicações da nova lógica de ação do estado para a educação municipal. Educação \& Sociedade, Campinas, v. 23, n. 80, p. 49-71, 2002.

ABU-DUHOU, I. Uma gestão mais autônoma das escolas. Brasília, DF: UNESCO; IIEP, 2002.

BAUER, H.H. Barriers against interdisciplinary: implications for studies of science, technology and society (STS). Science, Technology \& Human Values, Santa Clara, v. 15, n. 1, p. 105-119, 1990.

BERBEL, N.A.N. A problematização e a aprendizagem baseada em problemas. Interface, Botucatu, v. 2, n. 2, p. 139-134, 1998.

BIZZO, N. Ciências biológicas. In: BRASIL. Ministério da Educação. Orientaçôes curriculares nacionais do ensino médio. Brasília, DF: MEC, 2004. Disponível em: <http: |wwww.mec.gov.br>. Acesso em: 8 jun. 2006.

BONAMINO, A.; MARTINEZ, S.A. Diretrizes e parâmetros curriculares nacionais para o ensino fundamental: a participação das instâncias políticas do Estado. Educação \& Sociedade, Campinas, v. 23, n. 80, p. 368-385, 2002. 
Interdisciplinaridade e resolução de problemas...

BOUD, D.; FELETTI, G. The challenge of problem-based learning. London: Kogan Page, 1997.

CATANI, A.F.; OLIVEIRA, J.F.; DOURADO, L.F. Política educacional, mudanças no mundo do trabalho e reforma curricular dos cursos de graduação do Brasil. Educação \& Sociedade, Campinas, v. 22, n. 75, p. 67-83, 2001.

BRASIL. Ministério da Educação. Conselho Nacional de Educação. Parecer CNE/CP 9/2001. Diretrizes curriculares nacionais para a formação de professores da educação básica. Disponível em: <http: \ www.mec.gov.br>. Acesso em: 8 jun. 2006.

CARVALHO, J.S. Programa de Formação de Professores. São Paulo: USP; Pró-Reitoria de Graduação; Comissão Permanente de Licenciaturas, 2004. (mimeo).

CYRINO, E.; TORALLES-PEREIRA, M.L. Trabalhando com estratégias de ensino-aprendizado por descoberta na área da saúde: a problematização e a aprendizagem baseada em problemas. Cadernos de Saúde Pública, Rio de Janeiro, v. 20, n. 3, p. 780-788, 2004.

DE TOMMASI, L.; WARDE, M.J.; HADDAD, S. O Banco Mundial $e$ as políticas educacionais. São Paulo: Cortez, 1998.

DURHAM, E. Educação superior, pública e privada. In: BROCK, C.; Schwartzman, S. (Org.). Os desafios da educação no Brasil. Rio de Janeiro: Nova Fronteira, 2005. p. 197-240.

EDWARDS, A.F. Interdisciplinary undergraduate programs: a directory. 2. ed. Acton, MA: Copley, 1996.

FAZENDA, I. Práticas interdisciplinares na escola. São Paulo: Cortez, 2005.

INFANTE-MALACHIAS, M.E.; CORREIA, P.R.M. Superando barreras epistemológicas. Novedades Educativas, Buenos Aires, v. 19, n. 201, p. 52-57, 2007.

JANTSCH, A.P.; BIACHETTI, L. Interdisciplinaridade: para além da filosofia do sujeito. Petrópolis: Vozes, 2004.

JUPIASSU, H. Interdisciplinaridade e a patologia do saber. Rio de Janeiro: Imago, 1976. 
KEESEY, R. Transformations in disciplinary knowledge assumptions and their implication for reforming the undergraduate discipline. Issues in Integrative Studies, Ohio, n. 6, p. 82-125, 1998.

KLEIN, J.T. Interdisciplinarity: history, theory and practice. Detroit: Wayne State University, 1990.

LOPES, A.C. Os parâmetros curriculares nacionais para o ensino médio e a submissão ao mundo produtivo: o caso do conceito de contextualização. Educação \& Sociedade, Campinas, v. 23, n. 80, p. 389-404, 2002.

NORMAN, G.R.; SCHMIDT, H.G. The psychological basis of problem-based learning: a review of evidence. Academic Medicine, Pittsburgh, v. 67, n. 9, p. 557-565, 1992.

OLIVEIRA, D.A. A reestruturação do trabalho docente: precarização e flexibilização. Educação \& Sociedade, Campinas, v. 25, n. 89, p. 1127-1144, 2004.

PAYNE, S.L. Interdisciplinary: potentials and challenges. Systemic Practice and Action Research, New York, v. 12, n. 2, p. 173-182, 1999.

QUELUZ, A.G. Interdisciplinaridade: formação de profissionais da educação. São Paulo: Pioneira, 2003.

ROMM, N. Interdisciplinary practice as reflexivity. Systemic Practice and Action Research, New York, v. 11, n. 1, p. 63-77, 1998.

SAVIANI, D. A nova lei da educação: LDB, trajetória, limites e perspectivas. 5. ed. Campinas: Autores Associados, 1999.

STEMBER, M. Advancing the social sciences through the interdisciplinary experience. The Social Science Journal, Colorado, v. 28, n. 1, p. 1-14, 1991.

SANTOS, L.L.C.P. Formação de professores na cultura do desempenho. Educação \& Sociedade, Campinas, v. 25, n. 89, p. 1145-1158, 2004.

SANTOS, S. Para geneticistas e educadores: o conhecimento cotidiano sobre herança biológica. São Paulo: Annablume; FAPESP; SBG, 2005.

SANTOS, S. Everyday ideas about inherited disorders. Public Understanding of Science, Calgary, v. 15, n. 3, p. 259-275, 2006. 